\title{
Direct Discourse in the Greek Press: From Evidentiality to Subjectivity
}

\author{
Periklis Politis and Maria Kakavoulia \\ Aristotle University of of Thessaloniki \\ and Panteion University of Athens \\ ppolitis@jour.auth.gr/markak@panteion.gr
}

\begin{abstract}
Among the ways of discourse representation, direct quotation is the most explicit form of inclusion of a speech event in a discourse. Many researchers have reached the conclusion that Direct Discourse (DD) is the mode par excellence in news reports, and that its function is to ensure faithfulness to an original discourse. This article explores the validity of these claims by comparing the forms and functions of DD in two Greek newspapers, namely $I$ Kathimerini and $\mathrm{Ta}$ Nea. Our account relies upon a corpus-based approach to the study of DD forms and a qualitative analysis of a) the speech reporting verbs and b) the functions of DD in the news reports. Statistical information from the corpus provided that the most of the DD forms appeared in very divergent frequencies in the two newspapers. Concerning the functions of DD, we distinguished argumentation, dialogue that sets the scene of a conflict, interview reconstruction, evidence presentation, and legitimization. Moreover, reporting verb selection and source indication brought out the reporter's manipulation of discourse representation. Depth analysis proved that DD's functions are not simply restricted to faithfulness but are further related to the reporter's personal involvement in selecting and processing what to report.
\end{abstract}

\section{Introduction}

Discourse representation is closely related to news reporting, because the reporter's professional responsibility has to do with communicating newsworthy discourses to media 
audiences. Direct and Indirect Discourse are considered among the main grammatical devices available for discourse representation in news production. Several researchers have reached the conclusion that, in relation to Indirect Discourse (ID), Direct Discourse (DD) is the mode par excellence in written news reports, and that its function is, among others, to ensure faithfulness to a previously uttered speech or to provide factual information on socially important speech events (Bell, 1991: 207). Thus, DD is assumed to be irrelevant to the reporter's subjective stance towards reality. This paper explores the validity of such claims by comparing the forms and the functions of DD in two 'quality' Greek newspapers, namely I Kathimerini ("K") and Ta Nea ("N"). In particular, the proposed approach a) discusses a set of functions of DD that range from evidentiality to subjectivity, and b) describes aspects of stylistic variation in the language of the two newspapers.

Our account relies upon a corpus-based approach to the study of DD forms and a qualitative analysis (in a number of news articles) of the textual functions of DD in news reports. Among the subgenres of news reporting, we decided to examine the news article proper (hard news), because DD forms are very common there (Makkonen-Craig, 1999: 116). Data were collected by random daily selection of four news reports from the above mentioned newspapers for one month (January 2004).

\section{Theoretical framework}

We study the forms of DD according to Maingueneau's typology of reported discourse $(2000,2002)$ and the functions of DD according to Halliday's theory of register variation (1989). DD in the press is conventionally interpreted as being a literal quotation of a previous speech event that realized outside the written medium of the newspaper in a real time and place. As a mode of reporting, DD is based on a clear-cut distinction between two enunciative situations (Maingueneau, 2000:118), the reporting and the reported clause. The different types of DD are thus identified on the basis of dynamic interrelations between the reporting ("projecting" as Halliday would say) and the reported ("projected") clause. In press reporting, DD is often combined with other modes of discourse representation (Calsamiglia \& López Ferrero, 2003: 155). Therefore, in this paper we study not only a set of types and subtypes of DD, but also several boundary cases of DD, which merge direct with indirect modes of reporting. More specifically, we propose a typology of four main variants of DD: classic Direct Discourse, which we term 'Directly Reported Discourse' (DRD), Free Direct Discourse (FDD), Hybrid forms (HF) and Modalization in second discourse (MSD).

\begin{tabular}{|l|l|}
\hline \multicolumn{2}{|l|}{ DIRECT DISCOURSE } \\
\hline A. & Directly Reported Discourse (DRD) \\
\hline B. & Free Direct Discourse (FDD) \\
\hline
\end{tabular}




\begin{tabular}{|l|l|}
\hline C. & Hybrid Forms (HF) \\
\hline D. & Modalization in second discourse (MSD) \\
\hline
\end{tabular}

Table 1.

Generally, direct representations of discourse perform various functions in different discourse genres. In news reporting genre these functions are in part distinct from those in conversation or fiction. The exact words a newsmaker uses or is reported to have used are crucial to news reporting context, as they preexist independently in the world outside the text. However, given the technical and professional constraints over the journalistic practices, the editorial interference, and the multilayered processing of news editing (Bell, 1991), one could hardly speak of reproduction of 'original utterances' but rather of the constructedness of discourse representation (Baynham \& Slembrouck, 1999; CaldasCouthard, 1994). In other words, DD forms are functionally adjusted to particular situated practices and goals (Kakavoulia, 2002). Therefore, we study DD representation in news reporting stressing the situational dependency of the forms and functions of DD. More specifically, we conduct our discussion of functions based on the way Halliday (1989) analyses the "context of situation" of a given textual realization. In order to describe the stylistic profile of each newspaper (as concerns discourse representation) and to study aspects of situational context that make a difference as to how Greek press uses DD forms, we rely on Halliday's three "register variables": "tenor of discourse", "field of discourse" and "mode of discourse" (Eggins, 1994: 52-3). In relation to "tenor of discourse", we study the mutually exclusive values of 'formality' vs. 'non-formality'; in relation to the "field of discourse", we distinguish 'factuality' from 'non-factuality'. Concerning the "mode of discourse", we take into account that we are actually dealing with written data processed to accomplish specific informational purposes related to each newspaper's style policy, but we contrast nonetheless -within this general frame- between two semiotic materialities, namely the 'documentation' vs. 'orality' values, which respectively refer to the written or spoken character of the source quoted.

REGISTER VALUE

\begin{tabular}{|c|c|c|}
\hline TENOR OF DISCOURSE & FIELD OF DISCOURSE & MODE OF DISCOURSE \\
\hline $\begin{array}{c}\text { Formality } \\
\text { vs. } \\
\text { Non-formality }\end{array}$ & $\begin{array}{c}\text { Factuality } \\
\text { vs. } \\
\text { Non-factuality }\end{array}$ & $\begin{array}{c}\text { Orality } \\
\text { vs. } \\
\text { Documentation }\end{array}$ \\
\hline
\end{tabular}

Table 2.

Taken for granted that news reporting can exploit two modes of linguistic representation of events, the objective vs. the subjective mode -at least, this is a well-known claim of journalists-, we believe that the above mentioned three register variables (with their subsequent six values) support two major discursive strategies of reporting, namely 
evidentiality and subjectivity construction. As a strategy, evidentiality is related to journalism's dependency on anchoring information to extra-textual evidence. Subjectivity, instead, is related to a) practices that emphasize the reporter's own involvement in the stylistic appropriation and interpretation of the represented discourse, and b) the polyphonic character of DD strategies that allow the emergence of other 'voices' in the text.

Our approach takes into account previous contributions in the study of the form/function distinction of DD in news reporting, but it is differentiated from existing literature in respect to a) the regularities of functions accomplished by DD forms, and b) the proposed systematization thereof, which raises a probability claim in relation to the stylistic tendencies of each newspaper (Fairclough, 1995: 54-69).

Concerning the statistics of each particular form of DD, we found the following results:

\section{DIRECT DISCOURSE STATISTICS}

\begin{tabular}{|l|l|c|c|c|c|}
\hline \multicolumn{2}{|l|}{} & \multicolumn{2}{|c|}{ "I KATHIMERINI" } & \multicolumn{2}{c|}{ "TA NEA" } \\
\hline A. & $\begin{array}{l}\text { Directly Reported } \\
\text { Discourse }\end{array}$ & 60 & $=30 \%$ & 96 & $=29 \%$ \\
\hline B. & Free Direct Discourse & 8 & $=4 \%$ & 28 & $=8,4 \%$ \\
\hline C. & Hybrid Forms & 64 & $=32 \%$ & 148 & $=44,4 \%$ \\
\hline D. & $\begin{array}{l}\text { Modalization in second } \\
\text { discourse }\end{array}$ & 69 & $=34 \%$ & 61 & $=18,3 \%$ \\
\hline
\end{tabular}

Table 3.

As shown in the above table, the four categories of direct discourse are not equally represented in the two newspapers. Classical DD (DRD) has almost the same percentage in I Kathimerini (30\%) and Ta Nea (29\%), but -contrary to what one might expect- it is not the dominant mode among the studied variants in either newspaper. Next, Free DD (FDD), even though in the last place for both newspapers, appears twice as much in $\mathrm{Ta} \mathrm{Nea}(8,4 \%)$ than in I Kathimerini (4,\%). Moreover, statistics show that both newspapers, rather than DD, favor mixed types of discourse reporting such as Hybrid forms (HF) and Modalization in second discourse (MSD) (description to follow). Thus, $\mathrm{Ta}$ Nea shows the highest number of occurrences in hybrid forms (HF 44, 4\%), while I Kathimerini shows the MSD type of reporting as the most frequent category (34\%). It is noteworthy that $I$ Kathimerini shows a relative equivalence of occurrences between the three major types of reporting (DRD, HF, MSD), whereas Ta Nea shows greater divergence between these categories. 


\section{An analysis of the DD forms and functions in our corpora}

\subsection{Directly reported discourse (DRD)}

First, we examined the type of $\mathrm{DRD}$, conventionally considered as the most representative type of DD, in which the instance of the reporting discourse is syntactically distinct from the instance of reported discourse. In this major type we distinguish several subtypes on the basis of lexico-grammatical variations of the reporting clause.

\section{DRD (FORMS)}

\begin{tabular}{|l|c|c|c|c|}
\hline & \multicolumn{2}{|c|}{ "I KATHIMERINI" } & \multicolumn{2}{c|}{ "TA NEA" } \\
\hline $\begin{array}{l}\text { - speech-reporting verb } \\
\text { quotation (spoken or } \\
\text { written text) }\end{array}$ & 55 & $=91,6 \%$ & 82 & $=85,4 \%$ \\
$\begin{array}{l}\text { - summary or paraphrase } \\
+ \text { quotation }\end{array}$ & $\mathrm{X}$ & $\mathrm{X}$ & 9 & $=9,35 \%$ \\
$\begin{array}{l}\text {-nominal phrase }+ \\
\text { quotation }\end{array}$ & $\mathrm{X}$ & $\mathrm{X}$ & 3 & $=3,1 \%$ \\
$\begin{array}{l}\text { - prepositional phrase }+ \\
\text { quotation }\end{array}$ & 4 & $=6,6 \%$ & 1 & $=1 \%$ \\
\hline - dialogue & 1 & $=1,6 \%$ & 1 & $=1 \%$ \\
\hline
\end{tabular}

\section{Table 4.}

In the first subtype of DRD, the reporting clause as a projecting mechanism comprises a range of speech reporting verbs or expressions (Caldas-Coulthard, 1994) which contextualize the quotation of a previous speech or written document. This more 'conventional' type of DRD (also termed as 'classic DD') has -as expected- the highest frequency in both newspapers (" $\mathrm{K} "=91,6 \%, " \mathrm{~N} "=85,4 \%$ ). However, in Ta Nea only, we encountered a relatively rare (only a $9,35 \%$ of DRD occurrences) but interesting variation of DRD that replaces the speech reporting verb with a summary or a paraphrase of the discourse reported in the projected clause. In other words, the reporter summarizes the quoted discourse or 'translates' what is implied in the source's utterance (Tannen, 1989: 110-119; Fludernik, 1993). Thereby s/he gives strong contextual cues, which affect the reception of the quote. In this case, DD actually confirms the position taken by the reporter. Along the same line of variation within the reporting clause, we also encountered -mostly in I Kathimerini- a few cases $(6,6 \%)$ in which a prepositional phrase, semantically equivalent to a speech reporting verb, clearly marks the source of discourse, thereby 
framing at the same time its interpretation.

Rarely occurring in press news reporting, the 'dialogue' subtype of DRD has the form of a conversation between two speakers. Dialogue can either represent highlights of a public discussion previously summarized by the journalist or it can reproduce parts of an interview that took place between the reporter and an agent, a public figure probably. In this case, the reporter's questions pragmatically correspond to reporting clauses, whereas public figure's responses are the actual quotes.

In order to study the functions of each particular DD form and its impact on the stylistic variation of each newspaper we operated six triple combinations of register values, and studied the frequencies and regularities of their occurrences in our data. Statistical evidence showed different tendencies in the two newspapers.

\section{DRD (COMBINATIONS OF REGISTER VALUES)}

\section{"I KATHIMERINI"}

1. Formality / Non-factuality / Orality

2. Formality / Factuality / Orality

3. Non-formality / Non-factuality / Orality

4. Formality / Factuality / Documentation

5. Non-formality / Factuality / Orality

6. Non-formality / Non-factuality / Documentation

\section{"TA NEA"}

1. Non-formality / Factuality / Orality

2. Formality / Factuality / Orality

3. Formality / Non-factuality / Orality

4. Non-formality / Non-factuality / Orality

5. Formality/Factuality/ Documentation

6. Formality/ Non-factuality/ Documentation

$$
\begin{aligned}
32 & =53,33 \% \\
11 & =18,33 \% \\
11 & =18,33 \% \\
3 & =5 \% \\
2 & =3,33 \% \\
1 & =1,66 \%
\end{aligned}
$$

TOTAL: 60

$\begin{aligned} 27 & =28 \% \\ 23 & =24 \% \\ 20 & =21 \% \\ 18 & =19 \% \\ 5 & =5 \% \\ 3 & =3 \% \\ - & \end{aligned}$

Table 5 .

Both newspapers opt for orality indication, the representation of previous speech rather than the reproduction of written documents (documentation). Orality is first denoted in the reporting clause by the choice of specific speech reporting verbs or by the presentation of the source's personal / social identity, which varies according to the significance attributed to the source by the journalist reporting. In this case, the reporter's relevant choices indicate relative degrees of her/his subjective involvement.

Concerning the direct quotation itself, in " $\mathrm{K}$ ", 53,3\% of DRD occurrences meet the 'formality/non-factuality/orality' combination, as in the following example:

(1) "Horror movies have a certain therapeutic influence on the viewers (...)", said Mr. Dimitris 
Danias, a human behavior analyst (“K”, 31-1-2004).

In this case, features of orality are direct questions, exclamations, non-transposed deictics (e.g. personal pronouns and tenses of the previous speech), colloquialisms, discourse markers specific to the quoted speaker etc. Formality is characterized by language with no affective involvement, use of neutral and formal lexis, of complex syntactic structures etc. (Eggins, 1994:67) The 'voices' quoted are also authority persons, powerful social actors, institutional representatives, political leaders, high positioned civil servants, science experts or social organizations, which engage in declarations, announcements or explications rather than personal testimonies. While formality points towards an impersonal, non subjective language, the non-factuality value, which is very strong in " $\mathrm{K}$ " (71,6\% across all combinations), denotes subjectivity, because the statements presented as non-factual do not describe actual events or states of being but rather express different types of content, such as beliefs, evaluations, opinions, speculations, necessity statements (Almeida, 1992). Linguistic markers of non-factual statements are modal verbs and adverbs, evaluative adjectives, etc. This is in agreement with the " $\mathrm{K}$ "'s profile as an elitist newspaper, which generally addresses a more educated middle class audience.

A different combination is dominant in " $\mathrm{N}$ ", as it is also expected from the more populist profile of this newspaper. $28 \%$ of DRD forms appear in the 'nonformality/factuality/orality' combination.

(2) "We can't keep up with fixing repairs in the last few days. Nine in ten homes that had a problem had it in the solar water system" says the plumber, Mr. Dimitris Arvanitis, from the Greek Technical Coverage Company. ("N", 17-1-2004)

The use of non-formal language co-occurs primarily with factual statements (28\%) and secondarily with non-factual statements ( $21 \%)$, thus yielding a sum of $49 \%$ of the nonformality value for "N". Non-formality is expressed through a number of linguistic markers such as attitudinal and colloquial lexis, non-standard syntax etc. "N" uses everyday language to represent factual statements made by newsmakers (witnesses, 'common' people or even politicians) when they describe personal stories or specific states of being. In particular, factuality concerns those statements that denote past and present events or states of being, which are signaled mainly by the choice of verbs such as "concrete" or "descriptive" factuals (Almeida, 1992:245). Distribution of factuality vs. non-factuality assertions is remarkably dissimilar in the two newspapers. In " $\mathrm{K}$ ", DRD is used up to $71,6 \%$ to present opinions, evaluations, predictions etc. (53,3\% in formal tone and $18,3 \%$ in informal tone), whereas in "N", DRD forms use factual statements up to $52 \%$ ( $28 \%$ nonformal, $24 \%$ formal tone).

To conclude, DRD forms contribute to the persuasive 'showing' of professional competence (in the case of " $\mathrm{K}$ ") or to displaying of authentic evidence (in the case of " $\mathrm{N}$ "). The accomplishment of the above functions is favored by the disentanglement of 'voices', a structural and syntactic feature of DRD. Moreover, both newspapers perform a 
subjectivity function, in the sense that " $\mathrm{K}$ " favors the representation of different points of view, even though expressed in formal tone, whereas " $N$ " favors factual statements made by non powerful actors using familiar, informal language. However, both " $\mathrm{K}$ " and " $\mathrm{N}$ " share the combination "formality/factuality/orality" in their second place (" $\mathrm{K}$ " $=18,3 \%$, $" \mathrm{~N} "=24 \%$ ), a combination that indicates a tendency towards a more impersonal, "objective" discourse tepresentation.

\subsection{Free direct discourse}

A second variant of DD is Free Direct Discourse (FDD) which preserves all the grammatical features of DD but lacks one or more of its demarcation signals. We distinguished three major subvariants of FDD on the basis of the presence or absence of the three following criteria: quotation marks, speech reporting verb and source indication.

\begin{tabular}{|c|c|c|c|c|c|}
\hline \multirow{2}{*}{\multicolumn{2}{|c|}{\begin{tabular}{|l|l|}
\multicolumn{2}{|l|}{} \\
1 & 'zero quotation': \\
& + quotation marks \\
- speech reporting verb \\
- source indication
\end{tabular}}} & \multicolumn{2}{|c|}{$\begin{array}{l}\text { "I KATHIMERIN" } \\
(8)\end{array}$} & \multicolumn{2}{|c|}{$\begin{array}{c}\text { "TA NEA" } \\
(28)\end{array}$} \\
\hline & & 1 & $=12,5 \%$ & 13 & $=46,2 \%$ \\
\hline 2 & $\begin{array}{l}\text { a. } \\
\text { - quotation marks } \\
+ \text { speech reporting verb } \\
+ \text { source indication }\end{array}$ & 5 & $=62,5 \%$ & 8 & $=28,5 \%$ \\
\hline & $\begin{array}{l}\text { b. } \\
\text { written document : } \\
- \text { quotation marks } \\
+ \text { speech reporting verb } \\
+ \text { source indication }\end{array}$ & 1 & $=12,5 \%$ & 4 & ----- \\
\hline & $\begin{array}{l}\text { "énonciateur générique" } \\
\text { - quotation marks } \\
+ \text { speech reporting verb } \\
\text { - source indication }\end{array}$ & 1 & $=12,5 \%$ & $\mathrm{X}$ & $--\cdots-$ \\
\hline 3 & $\begin{array}{l}\text { - }+ \text { quotation marks } \\
\text { - speech reporting verb } \\
\text { - source indication }\end{array}$ & $\mathrm{X}$ & $\mathrm{X}$ & 3 & $=10,7 \%$ \\
\hline
\end{tabular}

Table 6. FDD (FORMS)

Given that the deictic center of DD types is that of the original utterance and given also, that FDD is shorn of the reporter's framing activity, we could say that of all DD types of 
direct speech presentation, FDD gives the impression that an incident is presently occurring. Even though FDD is not frequently used in either newspaper, overall it appears in $\mathrm{Ta} N e a$ twice as much than in " $\mathrm{K}$ ", showing again the tendency of "N" towards subjectivity as 'orality/factuality/non-formality' combination. The first subvariant of FDD, "zero quotation", totally lacks reporting clause (i.e. speech reporting verbs and source indication), but presents a stretch of discourse in quotation marks. Again, the two newspapers differ: Ta Nea favors the subtype of "zero quotation" (13 occurrences $=46,2 \%)$, whereas I Kathimerini has only one occurrence of this type $(=12,5 \%)$.

The second subvariant of FDD consists of DD originating from a speech event or a written document introduced by a speech reporting verb and a source indication but no quotation marks. I Kathimerini uses almost exclusively this subtype ( 6 of the 8 occurrences of FDD that equal to a $75 \%$ ), whereas $\mathrm{Ta}$ Nea shows a lower frequency of this subtype $(39 \%)$. An extract of discourse without quotation marks, in the form of a general statement using $3^{\text {rd }}$ person plural is Maingueneau's subcategory of "énonciateur générique" (2000:124), in which case the source is not specified, because a collective, unspecified 'voice' is quoted. Further, one form of FDD that "poses problems" (Maingueneau, 2000: 123 ) is the type of FDD with complete absence of reporting verbs, quotation marks and source indication, even though these can be inferred by the broader or more immediate context. Variational combinations in FDD appear in the same order of frequency as those of DRD.

\section{FDD (COMBINATIONS OF REGISTER VALUES)}

\section{"I KATHIMERINI"}

1. Formality / Non-factuality / Orality

2. Formality / Factuality / Orality

3. Formality / Factuality / Documentation

4. Non-formality / Non-factuality / Orality

"TA NEA"

1. Non-formality/ Factuality/Orality

2. Formality/ Non-factuality/Orality

3. Formality/ Factuality/ Orality

4. Non-formality/ Non-factuality/Orality

5. Formality/Non-factuality/Documentation

$$
\begin{aligned}
& 3=37,5 \% \\
& 2=25 \% \\
& 2=25 \% \\
& 1=12,5 \%
\end{aligned}
$$

Total 8

$$
\begin{aligned}
10 & =35,70 \% \\
6 & =21,42 \% \\
4 & =14,28 \% \\
4 & =14,28 \% \\
4 & =14,28 \%
\end{aligned}
$$

Total 28

Table 7.

$37,5 \%$ of " $\mathrm{K}$ "'s instances of FDD use formal language for non-factual statements attributed to several powerful social actors, whereas in "N" FDD is used mostly $(35,7 \%)$ to represent factual statements in non formal, everyday language, and, to a lesser extent, non-factual statements $(21,4 \%)$. 
(3) Forthcoming elections are not a football game so that voters choose the winner, Mrs. Aleka Papariga, general secretary of KKE (=Greek Communist Party) said yesterday. ("N", 26-12004)

"N"'s use of FDD (especially "zero quotation") is combined, in the same news article, with reporting chunks of speech from the same newsmaker (usually an interview with a politician, a group representative or an eye-witness of an event) rendering -even more than in DRD- the point of view of the newsmaker from within. It could be argued that FDD accomplishes a function of offering vividness and idiosyncratic nuances to the represented discourse, as the reporter pretends to give the ground to the speaker her/himself. FDD, in other words, becomes a way of showing (Mayes, 1990:351), dramatizing and reenacting a previous utterance, adopting the speaker's point of view.

\subsection{Hybrid forms}

As we moved, along the discourse representation spectrum, from the most direct forms towards the end of indirection, we examined those Hybrid forms (HF) of discourse reporting that are situated between the DD and ID poles. We assumed, in other words, that the relationship between DD and ID could be viewed as a continuum. These forms of discourse representation use a mix of direct and indirect modes of reporting, playing on boundaries with other types of reported discourse, in the presence of markers of subordination, transposition and punctuation (Waugh, 1995; Tuomarla, 2000; Rosier, 2002). This type of reported discourse takes away some control from the reporter in order to shift back to the actual discourse of the source.

\section{HYBRID FORMS}

\begin{tabular}{|c|c|c|c|c|c|}
\hline & & \multicolumn{2}{|c|}{ "IKATHTMERIN" } & \multicolumn{2}{|c|}{ "TA NEA" } \\
\hline $\begin{array}{l}\text { (14) Direct Discourse } \\
\text { +oti ('that') } \\
\text { complementizer }\end{array}$ & $\begin{array}{l}\text { Reporting clause } \\
\text { complementation } \\
\text { marker oti ('that') } \\
+ \text { quotation }\end{array}$ & 22 & 0,344 & 54 & 0,365 \\
\hline $\begin{array}{l}\text { 2. Autonymic } \\
\text { modalization }\end{array}$ & $\begin{array}{l}\text { Direct Discourse } \\
\text { segments (phrases) } \\
\text { in collocation/ } \\
\text { alternation with } \\
\text { other DRD forms }\end{array}$ & 16 & $=25 \%$ & 57 & $=38,5 \%$ \\
\hline
\end{tabular}




\begin{tabular}{|l|l|l|l|l|l|}
\hline & $\begin{array}{l}\text { "Islands" in the } \\
\text { reporter's discourse }\end{array}$ & 26 & $=40,6 \%$ & 37 & $=25 \%$ \\
\hline
\end{tabular}

Table 8.

The reporter selectively places in quotation marks (verbal or nominal) phrases or just a single word of the source. Among all types of DD reporting, the Hybrid forms are preponderant in $\mathrm{Ta} \mathrm{Nea}(44,4 \%)$ and less frequent in I Kathimerini $(32 \%)$. We distinguished three major subtypes of hybrid forms with divergent frequencies in both newspapers. First, 'Direct Discourse with that complementizer' is a case of ID that tends to switch or drift back to DD, which then takes the place of the full completive clause coming after a subordination marker, such as oti ('that'). This category, although quite old as a textual medieval practice (Bruña Cuevas, 1996; Marnette, 2003), is quite frequent in contemporary written press. In our data, DD with üôe ('that') occurs in roughly equal numbers for both newspapers ("K" $=34,4 \%, " N "=36,5 \%$ ) and, among the aforementioned three hybrid forms used by the reporters, it occupies the second place. The functions accomplished by this hybrid form do not severely differ from those accomplished by the two previously mentioned forms, DRD and FDD:

\section{DIRECT DISCOURSE + OTI ('THAT') COMPLEMENTIZER (COMBINATIONS OF REGISTER VALUES)}

\section{"I KATHIMERINI"}

1. Formality / Non-factuality / Orality

2. Formality / Non-factuality / Documentation

3. Non-formality / Non-factuality / Orality

4. Formality / Factuality / Orality

5. Formality / Factuality / Documentation

"TA NEA"

1. Non-formality/ Non-factuality/Orality

2. Formality/ Non-factuality/Orality

3. Formality/ Factuality/Orality

4. Non-formality/ Factuality/Orality

5. Formality/ Non-factuality/ Documentation

$$
\begin{aligned}
12 & =54,5 \% \\
4 & =18,1 \% \\
3 & =13,63 \% \\
2 & =9,09 \% \\
1 & =4,54 \%
\end{aligned}
$$

Total 22

$$
\begin{aligned}
20 & =37 \% \\
15 & =27,8 \% \\
8 & =14,8 \% \\
8 & =14,8 \% \\
3 & =5,55 \%
\end{aligned}
$$

Total 54

Table 9.

As seen in the table, the most frequently occurring combination of values for " $\mathrm{K}$ " is -once again- 'formality/non-factuality/orality' $(54 \%)$. This combination is by far more frequent than the subsequent one ('formality/non-factuality/documentation') which, however, in this form is slightly higher $(18,1 \%)$ than in previous forms. " $N$ ", on the other hand, uses this 
form in a slightly different way than DRD or FDD:

(4) Mr. Karamanlis did not fail to express his optimism that "in the end we will hold safe and perfectly organized Olympic Games" (“N” 19-1-2004)

Íon-formal language represents non-factual statements (evaluations, opinions, speculations, etc.) meeting the 'non-formality/non-factuality/orality' combination (37\%). Hence, this form functions as a distance establishing means, which enables the reporter to keep her/himself apart either from a language that it is not 'proper' or from a tone of language that $s$ /he cannot identify with. "N", much more than " $K$ ", uses this form to express subjectivity as idiolectal use of language, especially in the reported clause.

"Autonymic modalization" is an umbrella-term for the next two hybrid subvariants. The inclusion of a speech item or segment into quotation marks by a writer constitutes an "autonymic" operation on her/his own discourse (Maingueneau, 2000: 136-7). The "Segments of Direct Discourse", which occur in collocation with ID or summary, make up the first autonymic subvariant under study. Segments and/or phrases of DD are inserted partially in the completive clause. The category of DD segments or phrases has the highest use in $\mathrm{Ta} \mathrm{Nea} \mathrm{(38,5 \% ),} \mathrm{which} \mathrm{is} \mathrm{almost} \mathrm{double} \mathrm{than} \mathrm{in} \mathrm{I} \mathrm{Kathimerini} \mathrm{(25 \% ).} \mathrm{Usually}$ employed by academic or journalistic discourse, this form constitutes a routine practice of stylistic appropriation that gives a condensed reformulation of an original utterance (Maingueneau, 2002:193), merging thereby two points of view, the reporter's and the source's. However, this interpretive reshaping processed mainly in the reporting clause foregrounds the reporter's own point of view towards what $\mathrm{h} / \mathrm{she}$ is reporting. This form offers, by its very syntactic features, a place for the representation of the reporter's interpretation and, hence, favors subjectivity.

Concerning the functions accomplished by this form in our data, we found in the register values some similarities between the two newspapers:

\section{AUTONYMIC MODALIZATION (SEGMENTS) (COMBINATIONS OF REGISTER VALUES)}

"I KATHIMERINI"

1. Formality / Non-factuality / Orality

2. Formality / Non-factuality / Documentation

3. Non-formality / Non-factuality / Orality

4. Non-formality / Non-factuality / Documentation

5. Non-formality / Factuality / Documentation

$7=43,75 \%$

$5=31,25 \%$

$2=12,5 \%$

$1=6,25 \%$

$1=6,25 \%$

Total 16 
"TA NEA"

1. Formality/ Non-factuality/Orality

$21=36,84 \%$

2. Non-formality/ Non-factuality/Orality

3. Formality/ Factuality/Orality

4. Formality/ Factuality/ Documentation

$16=28,07 \%$

$8=14,03 \%$

$4=7,01 \%$

5. Non-formality/ Factuality/Orality

6. Formality/Non-factuality/ Documentation

$3=5,26 \%$

7. Non-formality/ ..../ Orality

$2=3,5 \%$

$2=3,5 \%$

8. Formality/ -.-----/ Documentation

$1=1,75 \%$

Total 57

\section{Table 10.}

The most dominant combination for both papers is the 'formality/non-factuality/ orality' one ( $\mathrm{K}$ " $=43,7 \%$, "N" $=36,8 \%$ ). They use this form to partially and metonymically insert non-factual statements that use formal language. Especially " $N$ " uses this interspersed form of quotation more than other $\mathrm{DD}$ forms in order to introduce discourse extracts from specific authority 'voices', such as Greek government and opposition politicians, trade union leaders, and to a lesser degree, international political leaders, European Commission officers etc. whose plans, opinions and evaluations are represented in a non factual non formal language register. However, " $\mathrm{N}$ ", in the second combination $(28,1 \%$ : "nonformality/non-factuality/orality'), shifts back to its usual non-formal language.

(5) The American Official repeated his views about "an unfair world and a harsh life" (...) ("N" 14-1-2004)

" $\mathrm{K}$ ", on the other hand, in the second place has the "formality / non-factuality / documentation' combination $(31,2 \%)$.

(6) According to the official report "Greek politics and the Refugees" (...) asylum seekers "are presented as possible terrorists, not as people trying to escape from terror" (" $K$ " 27-1-2004).

This clearly shows that " $\mathrm{K}$ " uses this form to provide fragments from written documents in order to present written evidence and truth claim to the reporter's projecting clause (Laroche-Bouvy, 1988: 120-21). "K"'s documentary evidence usually stems from government's official announcements, legal and political memorandums, statistical and research results, Foreign Office archives, official letters, written reports etc., and all of them have institutional character and politics oriented topics.

The third type of hybrids encountered in our data are the "islands" (Maingueneau, 2000: 129; Authier-Revuz, 1996), i.e. those fragments of discourse which are syntactically subordinate in the reporter's discourse and included in quotation marks. These islands of DD are usually attributable to the social actor's discourse and are distinguishable only by the presence of quotation marks and sometimes also by additional register features. They 
can be divided into textual or enunciative islands depending on the nature of the original source (written or spoken). "Islands" are the most frequent type of HF for I Kathimerini $(40,6 \%)$ and the less frequent hybrid types for $\mathrm{Ta} \mathrm{Nea}(25 \%)$. Statistically, the functions of this hybrid form present the following variational combinations:

\section{AUTONYMIC MODALIZATION ("ISLANDS") (COMBINATIONS OF REGISTER VALUES)}

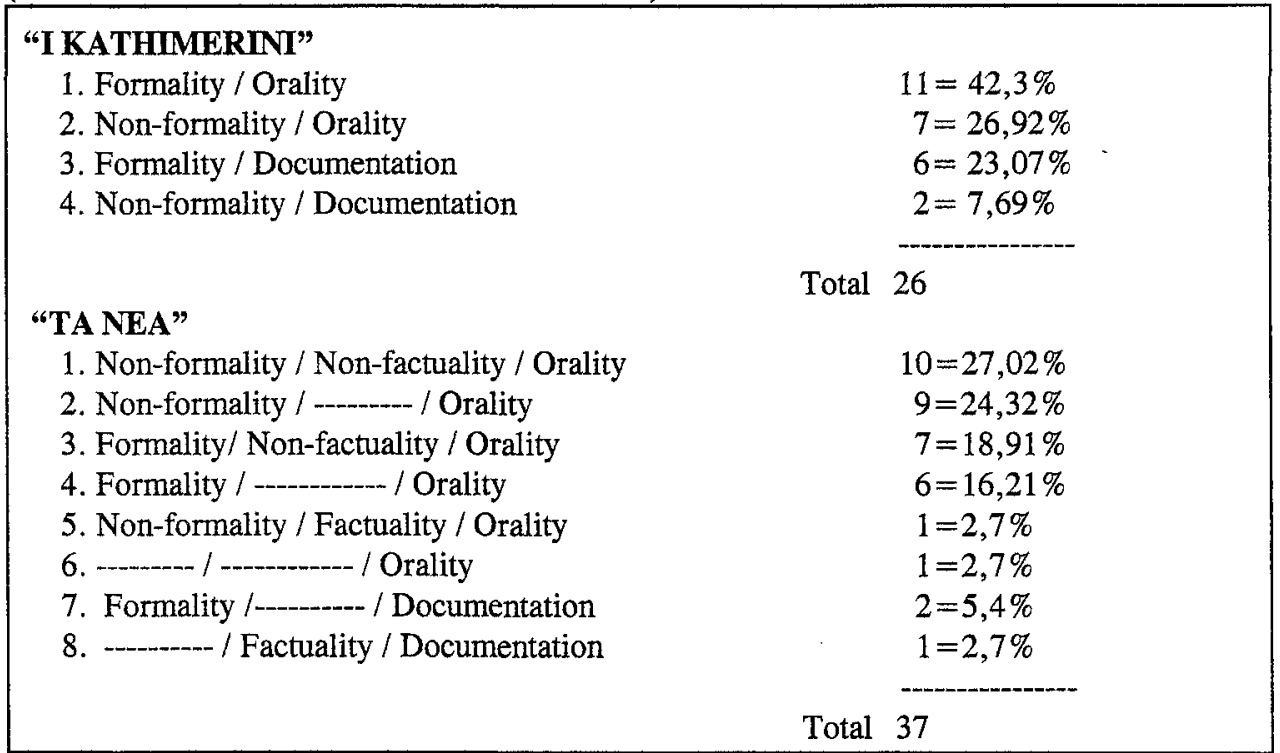

\section{Table 11.}

This hybrid form is almost totally linked to orality as the dominant register value for both newspapers: " $N$ "'s orality occurrences amount to a $92 \%$ and " $K$ "'s to a $69,2 \%$. Typically, " $\mathrm{K}$ " combines orality mostly with a formality tenor $(42,3 \%)$ and a non-formality one at lower rate $(26,9 \%)$, while the reverse holds for " $N$ " (35\% formal tenor, non-formal 52\%).

(7) The President of Iran, Mohamed Hatami, calls the people to "remain calm" (" $\mathrm{K}$ " 8-1-2004)

(8) Denktash supported that the Greekcypriot side is "at ease" with negotiations for the solution of the Cyprus problem ("N" 20-1-2004)

Formality is expressed in both newspapers by sociolectal expressions, such as words of high language variety (learned Greek), technical -not necessarily scientific- terms, typical expressions (specific contexts), unusual metaphors, etc. Mainly in "N", non-formality is related to orality features, such as exclamations, colloquialisms, slogans, everyday lexis, youth language, word-puns, euphemisms, discourse markers specific to the quoted speaker (idiolectal). Non-formality, in combination with non-factuality variable, is used in " $\mathrm{N}$ " $(27, \%)$ to express mainly positive or negative evaluations (by way of inserting idiolectal 
evaluative predicates).

Hybrid forms show expected differences between the two newspapers. When the quoted sources are actual written documents or official discourses (mostly in the case of "K"), the segments of DD in quotation marks are of the "neutral" type (Rosier, 2002). In this case, the Hybrid form is used by the journalists in order to distance themselves from the quoted segment, emphasizing their position as objective reporters. In the case of " $\mathrm{N}$ ", the selective and partial quotation of a source's actual speech foregrounds the "otherness" (Bakhtin) of the represented fragments of discourse and show an over marking activity of the journalist (Rosier, 2002). The same form can have a metalinguistic function as it can produce irony through contrastive language patterning, manipulation of meaning by style/ register contrasts. To conclude, the reporting clause in hybrid forms acquires a setting-thescene function.

\subsection{Modalization in second discourse}

Finally, those instances that signal the reporter's own discourse modalization (Modalisation en discours second, Charaudeau \& Maingueneau, 2002: 191) constitute a further extension of the hybrid forms of direct quotation. When a speaker does not focus on a primary (a source's) discourse, but on his/her own reporting discourse by inserting relevant prepositional phrases or anaphoric clauses (e.g. according to, as mentioned, etc.) in fact he modalizes his own discourse presenting/ foregrounding his discourse as a second discourse in relation to that of the source's. This variant draws attention to the authoritative sources cited, while explicit words are assigned to a particular agent without any communicative verb (the "inserted citation" form, Calsamiglia \& Ferrero, 2003:15). In this type of reporting, the reporter a) distances her/himself from the (claims of a) source's discourse, and b) points out the ways news production is processed by journalists. As already mentioned, among all types of DD reporting, MSD is the mode favored by $I$ Kathimerini (34\%) and less favored by Ta Nea (a mere $18,3 \%$ of total DD occurrences).

\section{MODALIZATION IN SECOND DISCOURSE}

\begin{tabular}{|l|c|c|c|c|}
\hline & \multicolumn{2}{|c|}{ "I KATHIMERINI" } & \multicolumn{2}{|c|}{ "TA NEA" } \\
\hline $\begin{array}{l}\text { Symfona me ('according to') } \\
\text { prepositional phrase insertion }\end{array}$ & 40 & $=57,9 \%$ & 27 & $=44,2 \%$ \\
\hline $\begin{array}{l}\text { Opos ('as') anaphoric clause } \\
\text { insertion }\end{array}$ & 28 & $=40,5 \%$ & 33 & $=1,6 \%$ \\
\hline $\begin{array}{l}\text { Prepositional phrase } \\
\text { insertion, e.g. kat'alles } \\
\text { ektimiseis ('according to } \\
\text { different estimations'), } k \text { ata } \\
\text { tis iäies piães ('according to } \\
\text { the same sources') }\end{array}$ & 1 & $=1,4 \%$ & 1 & \\
\hline
\end{tabular}

Table 12. 
The first subvariant (prepositional phrase insertion 'according to') shows the highest frequency in I Kathimerini $(57,9 \%)$ and a relatively lower frequency in $\mathrm{Ta} \mathrm{Nea}(44,2 \%)$, whereas the second subvariant ('as' anaphoric clause insertion) reverses the rate for both newspapers ( $\mathrm{K}$ " $=40,5 \%, " \mathrm{~N}$ " $=54 \%$ ). Concerning the functions accomplished by this form, both newspapers show the same dominant combination, namely the 'formality/factuality /orality'.

\section{MODALIZATION IN SECOND DISCOURSE (COMBINATIONS OF REGISTER VALUES)}

\begin{tabular}{|lc|}
\hline "I KATHIMERINI" & \\
1. Formality / Factuality / Orality & $25=36,23 \%$ \\
2. Formality / Factuality / Documentation & $20=29 \%$ \\
3. Formality / Non-factuality / Orality & $9=13 \%$ \\
4. Formality / Non-factuality / Documentation & $9=13,75 \%$ \\
5. Non-formality / Factuality / Orality & $2=2,9 \%$ \\
6. Non-formality / Non-factuality / Orality & $2=2,9 \%$ \\
7. Non-formality / Factuality / Documentation & $1=1,45 \%$ \\
8. Non-formality / Non-factuality / Documentation & $1=1,45 \%$ \\
& -69 \\
& \\
"TA NEA" & $21=34,4 \%$ \\
1. Formality / Factuality / Orality & $19=31,14 \%$ \\
2. Formality / Non-factuality / Orality & $9=14,75 \%$ \\
3. Formality / Factuality / Documentation & $6=9,83 \%$ \\
4. Non-formality / Factuality / Orality & $4=6,6 \%$ \\
5. Formality / Non-factuality / Documentation & $2=3,3 \%$ \\
6. Non-formality / Non-factuality / Orality & -21 \\
& Total $61 .-$ \\
\hline
\end{tabular}

Table 13.

In almost equal percentage for both newspapers (" $\mathrm{K} "=36 \%, " \mathrm{~N} "=34,4 \%$ ) this form is used to represent factual statements in formal language, while making explicit description of particular agents, indicating thereby a tendency towards evidentiality.

(9) As Mr. Parcharidis explained, the method can contribute to a cardiac health assessment of those patients who suffer from thalassemia ("I" 19/1/2004)

Moreover, especially for " $\mathrm{K}$ ", MSD form in the second and fourth variational combinations can be linked with authority and the adequate display of evidentiality, despite "shifts of frame" (Baynham \& Slembrouck, 1999: 441), because the sources represented (legislations, official announcements, etc.) are written documents (total $42,75 \%$ for " $\mathrm{K}$ ", only $14,75 \%$ for " $N$ "). 
(10) According to the E.E. research project, one in ten economic migrants is a University graduate ("K" 10/1/200).

" $\mathrm{K}$ " uses this form for authentification and distantiation. " $\mathrm{N}$ " makes use of mostly spoken discourse sources, but, has also an unusually higher rate of formality statements across variational combinations (almost $80 \%$ ), which indicates a distance from an affectively involved, explicitly subjective discourse representation. As shown by the register combinations, an evidentiality claim is potentially accomplished by MSD rather than by any other DD forms used, a pattern that emerges partly because it is favored by the form's structural features and partly because the newspapers show consistency in the use of this form/ function correlation.

\section{Discussion}

Taking into account that a) discourse representation is characterized by constructedness, especially in news processing contexts, and b) journalism is a practice of writing for a wider public, we consider that the register of newspapers is the outcome of a complex set of discursive strategies within a given context of situation. More specifically, concerning the newspapers under study, particular register tendencies were revealed. The "formality/non-factuality/orality' combination is dominant in " $\mathrm{K}$ " and cuts across all forms of DD used, showing thereby the stylistic identity of this newspaper. This combination serves "K"'s representation of spoken discourse attributed mostly to authority 'voices' (science experts, leading politicians, etc.). " $\mathrm{N}$ ", on the other hand, uses most of the DD forms to represent both authority 'voices' (mainly politicians) and 'ordinary' people, who are given familiar 'character', identity in the text by particular register values (nonformality, factuality and non-factuality statements). Concerning the hybrid forms of DD representation, they seem to increasingly become more commonly used in the Greek press, at least in newspapers which adopt a populist attitude, as for example, $\mathrm{Ta} \mathrm{Nea}$. On the other hand, newspapers like I Kathimerini, which stress the authority and authorization issues in news reporting, favor forms such as MSD, where the reporter indicates more strongly the source of speech by modalizing her/ his own reporting accordingly.

Moreover, DD is used not only to inform, but also to orient the reception of the 'voices' quoted within a specific interpretational and hence subjective frame that stems both from the societal stakes of each newspaper and the reporter's attitude towards what is being reported. Our data has shown that DD is mostly used for spoken discourse representation, more common in journalistic texts rather than in explicit quotes from written material. Thus, the only form with a higher degree of documentary evidence value is the MSD, while the rest of DD forms contribute to issues of subjectivity construction. 


\section{Conclusion}

Adopting a context sensitive view of the form/function distinction, we conclude that Direct Discourse -in all its studied varieties- shows systematic functional patterns, which depend on the context situated goals of each newspaper. It can be further argued that Greek quality press -as it is paradigmatically studied through the two newspapers ("K" and "N") oscillates between two tendencies that use different registers, but accomplish similar functions. Formality and non-factuality oriented statements attributed to important social actors characterize the more elitist profile of " $K$ ". The same newspaper draws more than "N" on documentary evidence does. Non-formal and factuality oriented discourse representation, attributed mainly to social actors concerned with Greek politics or internal affairs, is used by the more populist " $N$ ". However, despite register differences, both " $\mathrm{K}$ " and " $\mathrm{N}$ " eventually represent a multiplicity of 'voices', a polyphonic continuum, in which various types of subjectivity are represented by DD discourse strategies. The study of the ways the form/function distinction is systematically realized in the context of the two newspapers, allows us to question the supposed objectivity, faithfulness etc. attributed to DD forms. Direct Discourse does not serve as the vehicle for an exact reproduction of the wording of an original speech, but rather as a strategy to construct different images of subjectivity and to create the impression to the reader that $\mathrm{s} /$ he experiences the news stories, the information and the reported events through a variety of points of view.

\section{References}

Almeida, Eugenie (1991): “A category system for the analysis of factuality in newspaper discourse". Text 12(2): 233-262.

Authier-Revuz, Jacqueline (1996): "Remarques sur la catégorie de 1' 'îlot textuel' ". Cahiers du Français Contemporain 3: 91-116.

Baynham, Mike and Stef Slembrouck (1999): "Speech representation and institutional discourse". Text 19(4): 439-457.

Bell, Alan (1991): The Language of News Media. Oxford: Blackwell.

Bruña Cuevas, İanuel (1996): "Le discourse introduit par Que". Le Français Moderne 54(1) : 28-50.

Caldas-Couthard, Carmen Rosa (1994): “On reporting reporting: The representation of speech in factual and factional narratives”. In M. Coulthard, ed., Advances in Written Text Analysis. London: Routledge, 295-308.

Calsamiglia, Helena and Carmen López Ferrero (2003): "Role and position of scientific voices: Reported speech in the media". Discourse Studies 5(2): 147-173.

Eggins, Suzanne (1994): An Introduction to Systemic Functional Grammar. London: Pinter. Fairclough, Norman (1995): Critical Discourse Analysis. London \& New York: Longman. Fludernik, Monika (1993): The Fictions of Language and the Languages of Fiction. London: Routledge.

Halliday, M.A.K. (1989): "Register Variation". In M.A.K. Halliday and R. Hasan, Language, Context and Text: Aspects of Language in a Social-Semiotic Perspective. Oxford: Oxford 
University Press, 29-43.

Kakavoulia, Maria (2002): “On reported discourse: Recording speech and thought in modern Greek literary and press narrative”. In C. Clairis, ed., Recherches en linguistique grecque. Paris: L'Harmattan, vol. I, 251-255.

Laroche-Bouvy, Danielle (1988) : "Emergence de l'interaction verbale dans la presse écrite: fonction de la citation". In P. Charaudeau, ed., La Presse. Produit, Production, Réception. Paris: Didier, 113-130.

Maingueneau, Dominique (2000): Analyser les textes de communication. Paris: Nathan. . (2002): "Discours rapporté". In P. Charaudeau and D. Maingueneau, eds., Dictionnaire d'analyse du discours. Paris: Çditions du Seuil, 190-195.

Makkonen-Craig, Henna (1999): "Speech quotation in newspapers as a form of language use". SKY Journal of Linguistics 12: 111-144.

Marnette, Sophie (2003): "Indirect discourse in a diachronic and pangeneric corpus of French: Forms and strategies". Forum for Modern Language Studies 39(4): 414-426.

Mayes, Patricia (1990): "Quotation in Spoken English". Studies in Language 14(2): 325-363.

Rosier, Laurence (2002): "La presse et les modalités du discours rapporté: l'effet d'hyperréalisme du discours direct surmarqué". L'information grammaticale 94: 27-32.

Tannen, Deborah (1989): Talking Voices: Repetition, Dialogue and Imagery in Conversational Discourse. Cambridge: Cambridge University Press.

Tuomarla, Ulla (2000): La citation mode d'emploi. Sur le fonctionnement du discourse rapporté. Helsinki: Academia Scientiarum Fennica.

Waugh, Linda (1995): "Reported Speech in Journalistic Discourse: The Relation of Function and Text". Text 15(1): 129-173. 